\title{
Navigating New Worlds: A Real-Time Look at How Successful and Non-successful First- Generation College Students Negotiate their First Semesters
}

\author{
Erik E. Morales, $\mathrm{PhD}$. \\ Associate Professor, Elementary and Secondary Education \\ College of Education, New Jersey City University \\ 2039 Kennedy Blvd, Jersey City, NJ 07305-1597, USA
}

Tel: 1-201-200-2428Ｅ-mail: Emorales2@njcu.edu

Received: December 12, 2011

Accepted: January 6, 2012

Published: May 15, 2012

doi:10.5430/ijhe.v1n1p90

URL: http://dx.doi.org/10.5430/ijhe.v1n1p90

\begin{abstract}
This study of fifteen first generation American college freshmen documents their initial semester with a focus on factors and dispositions contributing to eventual success or failure. Students were identified prior to campus arrival, allowing for immediate and real-time data collection as they were experiencing the beginning of their college careers. Key factors identified and explored include the importance of active help-seeking, effective management of unstructured time, the dangers of underestimating academic rigor, and the crucial nature of the first two weeks. Suggestions for how the findings may be of practical use, as well as further research implications, are included.
\end{abstract}

Keywords: First generation, College students, First semester, Active help-seeking, Free time

Documenting and understanding how students manage their initial college experience remains an elusive but pressing research goal (Clark, 2005; Hudson, et. al. 2002, Jacobs \& Archie, 2008; Phinney \& Haas, 2003). The potential importance of this understanding is enhanced by the widely held belief that how well (or poorly) students negotiate their early college experience has significant impact on their chances of ultimate graduation and success (Clark \& Cundiff, 2011; Hughes, 1987; Lang, 1986, 1992). Illuminating the need to better understand students' performances once admitted to college, but before graduating, are statistical data indicating that of all first time full time freshmen in the United States, only 57\%will complete their degrees within 6 years. Furthermore, when looking at Hispanic and African American students (those disproportionately more likely to be first-generation), these percentages drop to $42 \%$ and $49 \%$ respectively (United States Department of Education, 2009). Finally, the overall experiences of American college freshmen have recently become of greater concern given a recent study cited in AFT On Campus (2011), indicating that the nationwide freshman class of 2010 reported higher stress and lower emotional health than in previous years .

As noted above, it is often the initial college experiences that portend the likelihood of eventual graduation. And, while early college experiences can be challenging for many types of students, students who are the first in their families to attend college tend to have greater and more severe difficulties with this transition (Clark, 2005; Gardner \& Karri, 2011).

Why low socioeconomic and ethnic minority students often have difficulty transitioning to college is a broad question answered in part by the voluminous research done on the "achievement gap" between poor/minority students and their wealthier (and often white) counterparts. Primary reasons are summarized well by Gardner (2007) and include unequal school funding, language barriers, health and nutrition disparities, lack of cultural and social capital, parents' lack of formal education, and the consequences of historical and current racism. And while the specific manifestations and consequences of all these issues are beyond the scope of this research, they do exist and, at least in part, account for greater difficulty transitioning to college for specific populations.

Accentuating the value of better understanding the transition process is the notion that college attendance remains the primary means of ascending to and/or remaining middle class (Perna, 2005). This reality makes understanding successful and unsuccessful approaches to transitioning to college important. Furthermore, given the aforementioned difficulties faced by many first generation and lower socioeconomic status college students, for this group in particular the value of 
understanding this process becomes crucial. The need to better understand what helps minority and at-risk students to achieve remains pressing (Seidman, 2007).

While there have been numerous studies providing insights into, and theories of, the performance of college students and how they adjust to college life (Astin 1993; Pascarella \& Terenzini 1991; Sedlacek 1996; Tinto 1993), and much research has specifically focused on how first generation college students have managed this transition (Attinasi, 1989; Seidman, 2007; Terenzini et al., 1994) these studies have tended to use quantitative regression analysis to tease out what variables correlate with eventual success (see Bai \& Wei, 2010 for a recent example), and conclude that various degrees of both social and academic integration correlate with eventual success, and a lack of these often lead to attrition. Additionally, characteristics such as self-efficacy (Dennis et. al., 2008), expectancy for success (Hu \& Kuh, 2002), and strong work drives (Ridgell \& Lounsbury (2004), have all been presented as keys to academic success for college students.

While these works have laid important big picture groundwork, there have been few studies that have attempted to qualitatively document the transition process in real time; as the students are experiencing the process. One recent study that has come close to capturing these rich data is Clark's (2005) work focused on how second semester college freshmen "strategized" as they made their way through their first year of college. However, Clark's work was limited to commuter students at a commuter college and did not capture data during the crucial first semester. Given the increasing number of first generation college students nationwide, there remains an urgent need to understand and serve this population, especially during the critical first semester (Horwedel, 2008).

\section{Guiding Research Questions}

While we know that a successful transition to college is often a prerequisite to eventual success, there are several significant questions that are still in need of exploration, and that have been used to guide this research initiative:

- How might initial obstacles and problems facing students be addressed and solved during the course of the students' first semesters?

- What types of relationships (both peer and faculty/staff) might students have found valuable to successful transitions? Furthermore, what in particular was efficacious about these relationships?

- How might the individual natures of "successful" and "non-successful" first semesters differ? Furthermore, what accounts for these differences?

\section{Method}

This longitudinal study covered the initial college semesters of fifteen first generation college students in real time as they experienced their first semesters of college. All of the students were beginning their college careers as freshmen during the fall semester of 2010, and did not have parents who had attended college.

Subsequent to earning approval from the Moderately Sized Private University's (pseudonym) Institutional Review Board, the researcher worked with the admissions office to identify potential interviewees during a summer orientation prior to their freshmen year. This crucial step served two essential purposes: First, it allowed the researcher to begin gathering data from the students immediately upon beginning their freshman semester. Second, it allowed the researcher to create a potential pool of students who all shared highly similar levels of academic preparedness (all student participants had between 2.8 and 3.1 high school grade point averages). By holding pre-college academic backgrounds relatively consistent actions and outcomes of the first semester could be fairly compared between and among students.

Moderately Sized Private University is located in a suburban area in the northeast United States. According to The Princeton Review's Complete Book of Colleges (2010), it is predominantly white, moderately selective, and has an enrollment of about 5,000 students. The University is primarily known for its undergraduate majors in business administration and competitive athletic teams.

The basic criteria that students had to meet were being the first in their families to have gone to college (this included older siblings), the high school GPA parameters discussed earlier, and the willingness and availability to be interviewed multiple times during the fall semester. Potential sample students completed a Participant Identification Form which verified that they met the above criteria and gathered some additional pertinent demographic information (age, ethnicity, previous schools attended, and updated contact information). Students were told that the researcher would ultimately share findings with them and that no identifying information would be used.

Initially, seventeen students were identified as meeting the criteria and completed forms. Two did not return the researcher's start of the term outreach, leaving fifteen participants, all of whom voluntarily made themselves available for all facets of the research process. The student participants also agreed to provide the researcher with access to their grades at the end of the semester to document eventual academic outcomes. 
Of the fifteen students in the sample the average age was 18 . There were eight males and seven females. All all of the students were the first in their families to go to college. Six of the students identified themselves as "White," five identified as "Hispanic" (having parents or grandparents who immigrated to the United States from the Spanish speaking Caribbean or South America), and four identified as "African American."

\subsection{Qualitative Methods}

This relatively large qualitative sample remained manageable and allowed for detailed and in-depth analysis. The researcher primarily utilized detailed, semi-structured interviews to gather data. The goal of the interviews was to understand and document how the students were experiencing their first semesters of college, as such, qualitative interviewing was a logical and effective means of inquiry (McCracken, 1988; Spradley, 1979).

Qualitative methods have been well documented as effective means of documenting individual experience and perspective (Bogdan \& Biklen, 1982; Ely, 1991; Watson \& Watson-Franke, 1985). Specifically, the concept of phenomenology was utilized in this study. Generally speaking, phenomenology emphasizes the subjectivity of experience as well as the need to view those experiences from the individual interviewee's point of view (Bogdan \& Biklen, 1982; Geertz, 1973). Furthermore, from a psychosocial perspective, the ongoing lengthy interviews served to build trust and intimacy between the interviewees and the researcher. The intention was for this intimacy to engender sincerity, comfort, openness, and ultimately rapport during the interviews, thus producing findings that are as authentic as possible.

The initial interview for each student took place at some point during the first week of the semester. Subsequent interviews were conducted approximately every three weeks after the first one. These three week intervals were designed to allow enough time for the students to reflect on their experiences, yet still allowed for continuous, real-time capturing of the acclimation process. Each interview lasted between ninety minutes and two hours.

\subsection{Data Analysis}

As the research process unfolded, data collection and analysis were conducted in a virtually simultaneous manner until the data saturation point was met (Rubin \& Rubin, 1995). The data saturation point referred to the point at which collecting new data did not contribute significantly to the ultimate findings.

The overall data analysis approach was consistent with the inverted triangle paradigm (Kirk \& Miller 1986), where data are first coded for broad themes identifying the challenges students faced and some of the ways they were responding. The research then focused more specifically on the details of these responses as well as the quality of the outcomes.

Consistent with qualitative research norms, three basic means of ensuring accuracy were implemented: triangulation, member checking, and an external audit (Creswell, 2005). Triangulation involved the process of identifying multiple sources of evidence in order to support a specific finding. This was the primary means of ensuring accuracy. The researcher documented student claims and then identified at least three evidentiary statements for each. Member checking was also relied upon heavily. Member checking refers to the process of checking back with a participant in order to confirm/clarify a specific finding. Member checking was often done via email in-between interviews and at the beginning of subsequent interviews. External auditing was also utilized. An external audit requires the researcher to share raw data with an experienced researcher in the field in order to compare interpretations and reach consensus. The researcher shared unadulterated interview transcripts with a colleague and used that colleague's interpretations to inform his own.

Through fair, skillful and consistent implementation of these tools, the researcher hopes to ensure results that are as accurate, meaningful, and genuine as possible

\section{Findings/Themes}

Resulting from the systematic review of data outlined previously, four especially significant themes arose: The Importance of Active Help-seeking; Managing Free Time; The Dangers of Underestimating Academic Rigor; and "Early Diligence" -The Crucial Nature of the First Two Weeks.

It is important to note that subsequent to their first semesters, of the fifteen study participants, eight were identified as academically successful and seven as unsuccessful. "Success" was operationalized as the students earning a minimum of a 2.75/4.0 grade point average (gpa) at the end of their first semesters. "Unsuccessful" students were those who had earned anything below a 2.75/4.0 gpa. The unsuccessful students $(\mathrm{N}=7)$ entered college with an average high school GPA of 3.0 and finished their first semester with a 2.4, while successful students $(\mathrm{N}=8)$ began with a 2.9 and ended up with a 3.0. 
What follows is a brief description of each of the previously mentioned themes, as well illustrative examples and explanations.

\subsection{The Importance of Active Help-Seeking}

A good number of the successful students (6/8) could be described as active help seekers in that when they encountered questions, obstacles, uncertainty or confusion, their immediate reaction was to seek out help from available resources. And while the resources ran the gamut (from peers, upper classmen, counselors, professors, websites, and student handbooks), a key attribute was the students' willingness and desire to not just reach out, but to acknowledge the issue in the first place.

The importance of this active help seeking behavior cannot be understated, especially considering the often complex and confusing rules, regulations, processes, sequences and procedures prevalent in many colleges, including the one that these students were attending. Furthermore, the complexity of said rules appeared compounded by the students' statuses as the first in their families to attend college. Below, Janet (ultimately unsuccessful) describes her attempt to understand her academic requirements. Her description is reflective of the confusion and anxiety experienced by many of these students:

I don't know why this stuff is so complicated. You need one (course) from this group, one from that, but this one needs a pre-requisite and that one needs this and that. And oh yea, that one needs a co-requisite! I was like, what the hell is a co-requisite? ...then the credit stuff, like someone said that this one class was three credits, but that the credits don't count. I'm like, what does that mean? Why would you take a class that don't count? It's like another language they talkin' about. (Janet, 18, African American Female)

Adding to the importance of and need for help seeking behaviors is the reality that most of these students could not count on parents or family members to help translate the somewhat esoteric language and customs found in college catalogs and websites. In order to succeed, students had to move away from their comfort zones and seek help from beyond their usual social network. Often, those who were unwilling or unable to admit ignorance and seek answers paid the price of confusion, anxiety, and an overall sense of bewilderment.

Interestingly, while a good majority of the entire sample group (13/15) did articulate confusion over regulations, the nature of their responses to the confusion was not spread evenly across the successful and non-successful students. Perhaps not surprisingly, 6/8 successful students did actively seek out help, with only $3 / 7$ of the non-successful students doing so.

Exactly how the students sought out answers and procured information revealed some interesting patterns. A variety of informational sources were utilized to answer questions students had about advisement, course registration, credit values, necessary tests, pre and co-requisites, and course sequencing. The most popular sources for students who did actively seek out answers (9/15) were 1. Institutional websites (7/9), 2. Peers (6/9), 3. Professors/staff (6/9), 4. Hard copy resources (catalog/student handbooks and handouts.) (5/9), and 5. Assigned advisors/counselors (3/9).

The fact that institutional websites were the most common sources appeared to reflect both the 24 hour ease with which that data source is available, and the technological ubiquity that imbues current youth culture.

Throughout the interviews, when students responded to questions about why they chose the methods of acquiring information that they did, they consistently pointed to ease, proximity, accessibility, and immediate availability. This was most pronounced when students explained why they relied so much on the Internet for gathering information of all types. Omar's rationale for continuously turning to the Internet illustrates what many of the students expressed:

I'd much rather just go online to get what I need. It's a lot easier because that way I can do it when I want and I don't have to go nowhere or anything.... I heard that I could maybe CLEP (College Level Examination Program) some of the Spanish classes to get credits and what not, so I just looked it up to see what I needed. (Omar, 18, Hispanic Male)

On the surface this may not seem like a problem. But issues arose for these students during situations when, contrary to their beliefs, websites were not adequate substitutes for in-person counseling and advisement. Omar continues:

...so when I went to take the test I found out that I had the wrong date or something and I also needed to get some kind of form in beforehand or whatever. So I missed it. I guess I didn't read the whole thing or they didn't update it or whatever...I probably should have talked to someone in person.

The fact that such a relatively large percentage of students used their peers as sources of information reflected some of the same perceived benefits mentioned for going on-line. Peers were there, unthreatening, and required little effort. But 
perhaps even more than the Internet, their information was not always accurate. Multiple students talked about how many rumors and questionable pieces of information seemed to flow between and among the students.

It is worth noting that when it came to human sources, students were more likely to seek help from those already within their social comfort zones (i.e. sources with whom students were already comfortable), rather than reaching out to people whom they had not yet met or with whom they were not especially comfortable, even when those people were formally assigned to them. When asking students why they chose the informational sources they did, most students referred, either directly or indirectly, to relying on people who they already knew. Christopher's response illustrates s what many of the students reported:

Q. You mentioned that you are sometimes confused about your classes and what you need to make progress with your degree. Do you seek out answers to your questions, and if so, how?

A. It's hard to know what to do, with classes and all and like how to know what it all means...A lot of it is stuff you just hear from other students, older kids and all, or going on-line or whatever. That's what I mostly count on.

\section{Q. You have not mentioned talking with a counselor or advisor, why not?}

A. I don't know. I guess I'm just lazy, like making an appointment and all, it's like too much sometimes. I'd rather try to find out on my own...the few times I did talk to an advisor I left kind of confused. I felt rushed but also I didn't really know what to ask. I wish I could just have a list of all the classes I need and when to take them...It seems like there is almost too much choice. (Christopher, 19, Hispanic Male)

As with many of the students, Christopher's reluctance to actively seek answers from advisors or counselors appeared to stem from his perception that there is a lack of a trusting and comfortable relationship, as well as an admitted degree of lethargy.

\subsection{Managing Free Time}

Among the more challenging transitional issues experienced by these students was getting acclimated to the relatively large amount of "free" and unstructured time they found available to them. This challenge was most pronounced during the first three weeks for two major reasons: First, coming from high school, students were simply unaccustomed to having class for a few hours a day on three or four days a week. That combination of increased time and reduced structure took some getting used to and even proved academically lethal for some of the students. Second, because the first few weeks had relatively few assignments due, there was little apparent urgency to use the time to do class work.

Rayshawn's two excerpts capture how many of the successful students were able to gradually acclimate themselves to the change in time and structure:

Week two of semester: It's like I don't know what to do with myself, I got so much time without having to be anywhere....My last class ends on Wednesdays at like 2, and I don't have class again until Monday afternoon, that's like five days of just being able to chill...there's not that much work yet, I mean, there's readings and stuff, but nothing that I have to actually do, like in the library or writing a paper and what not.

\section{$Q$. What do you do with all that time?}

A. Sleep, hangout out, play some ball...I even get bored sometimes. (Rayshawn, 18, African American Male)

\section{Week eight of semester: Q. I don't hear you talking about free time anymore. Why do you think that is?}

A. Man! that work caught up with me real quick. I couldn't believe it, I even started falling behind. It felt like I had so much time to do an assignment, then all of a sudden it was due the next day and I didn't even start it yet... Now I make sure to go to the library every week day, no matter what. When I'm there it's just like time to get to work, being there is my signal to get stuff done... it took a while, but I realized I had to try and start stuff early do readings and stuff even if it wasn't going to be checked right away...going there (the library) all the time helped me build the structure that I didn't have since high school.

Like Rayshawn, a good number of the successful students (5/8) responded to their large amount of open time by creating their own structure before it got too late. In fact, many of them commented on how the semester "started slow" but seemed to "speed up."

Just as catching up with the new time realities of college was an important skill for the successful students, many of the unsuccessful ones (6/7) could trace their lack of success, at least in part, to their ultimate inability to manage what felt like abundant free time. Carla's late wake- up call reflects how many of these students found themselves too far behind, too fast. 
Week two of semester: College is so much better than high school, it's not even funny. I feel like a grown-up now, not having to get up all early and be here or there all day with someone telling you want to do...I love it (being autonomous), I can do stuff at my own pace.

Week eight of semester: Q. You seem to struggling with most of your classes, what's going on?

A. I just feel, like, so overwhelmed. I wake up and I'm like, okay, now and I am really gonna catch up, but then I look at what I have to do, and stuff that's already late and I'm like, damn, what's the use?. ... I feel like I just got here, like the semester just started, but then I look up and Thanksgiving is right around the corner and my teachers are already talking about finals, and I'm like, where did the time go? (Carla, 18, Hispanic Female)

While the exact cause of Carla's inability to manage her time (immaturity, lack of a work-ethic, disorganization, etc.) may not be $100 \%$ identifiable, the consequences of that inability are clear. As with many of the unsuccessful students, the first semester "moved to fast" and by the time they realized it, they felt it was too late.

\subsection{Underestimated Academic Rigor}

Many of these first generation students had difficulty responding to the academic rigor and expectations of college coursework. Eleven of the fifteen students graduated from public urban high schools, and though all of the students had relatively high GPAs, most did not view themselves as ready for the new academic expectations. Somewhat surprisingly, the successful students were actually less confident about their academic preparedness than their unsuccessful peers. In fact, out of the ultimately successful students, only $3 / 8$ initially indicated high confidence about their ability to succeed academically at the college level, where as $5 / 7$ of the unsuccessful students did so. While this may seem counter-intuitive, after speaking with students throughout the semester it became clear that often it was their initial academic insecurity, combined with an honest acknowledgement of that uncertainty, that eventually lead to more diligence and an accompanying sense of focused effort. These experiences differed greatly from the unsuccessful students who tended to either not notice their possible lack of preparation, or refuse to acknowledge it openly.

A look at Peter (a successful student) and Anthony (an unsuccessful student) at both the beginning and end of the semester illustrates how the propensity of the two groups to accurately self-assess differed, and the resulting effect on academic effort and consequent performance:

Week two of semester: As soon as I got them (the course syllabi) I knew I might be in trouble....My teachers (in high school) always told us how hard college was going to be, they'd be like "you're not going to get away with that in college," and now I'm realizing they were right. High school was pretty easy, it was just about doing your work and not being a pain in the butt. If you did that you got A's. Now I feel like if I'm not on top of things I could pay the price. (Peter, 18, Turkish/Russian American Male)

Week thirteen of semester: Q. When we spoke during week two you expressed concerns about college work possibly being too difficult. Now that the semester is almost over, how do you think you are doing?

A. I feel good because I feel like I've been able to stay on top of things. From the start I knew it wasn't going to be easy, so when the challenges came, I felt like I was ready...I knew my high school wasn't the best school-wise. I mean we had great football and basketball teams, but academics wasn't high on the list. So I knew I'd have to be on top of things to keep my grades up. I knew it was going to be a new ball game and I was right...the most important think was making sure to start stuff early, to do the assignments before the last minute..this way I was always ready, and when stuff did come up I wasn't totally thrown off.

Week two of semester: Q. Do you feel like you are ready for college work?

A. Yeah, I always did pretty good in school. I'm not a great test taker, but my grades were always good, I can usually find a way to do good...I don't think this (college) will be that big a deal, I mean I have to do my work, don't get me wrong, but I don't think it's gonna be that bad....My cousin (a student at another institution) said he don't really go to class, he said all you got to do is get the notes, then take the final. (Anthony, 18, Italian American Male)

Week thirteen of semester: Q. When we spoke during week two you felt confident about your ability to handle college level work but last time we spoke you said you were struggling in some of your classes. Now that the semester is almost over, how do you think you are doing?

A. I gotta be honest, I am really not doing good...I think I did kind of underestimate how hard it would be. I mean, it's not that I can't do the work, I know I can, it's just that I wasn't really used to working hard because I never had to...but by the time I realized that that same old relaxed style wasn't going to cut it.... I don't know, it just kind of got away from me I guess... I feel like it's too late now. Like I pretty much just wasted this semester. 
In both students' stories it becomes clear that the degree to which they accurately assessed their academic readiness lead to either vigilance or passivity in regards to how much they focused on academics, and in the end made a significant impact on how well (or poorly) they ended up doing.

\subsection{Early Diligence: The Crucial Nature of the First Two Weeks}

As mentioned above, the students (both the successful and unsuccessful) repeatedly described the initial semester with terms like "moving quick," "going fast," and "rushing by." Because of the apparent speed with which the semester moved, those who were concerned about their level of preparedness began with a high degree of diligence, while those who were not, did not.

This pattern was evident in many student transcripts to varying degrees, but Trevor's (successful student) and Manuel's (unsuccessful student) reflections are particularly explicatory, and illustrate this phenomenon in especially clear terms:

Week after End of Semester. Q. Now that the semester is over, looking back, what do you think was most significant in getting you the final grade results that you received?

A. ...It was the fear, that was I think the biggest thing for me. I mean, I had all these people, my mom and all, counting on me and it was scary. You hear "college" and it's like a really scary thing. So I came here scared, but in a good way. That sounds crazy, "a good scared" but it helped. I had to make double sure that I did all I could do. I was ready from the start...I remember after the first class I was going to the library and my boy was like, "Where you going? The class just started." And I was like, "I'ma do the reading that's due next class." And he was like, "There's no paper or test or nothing on it." And I was like, "I don't care, I can't be falling behind."...It made a big difference (working hard from the beginning of the semester), because I was just on top of stuff.....before I knew it, I was getting A's and able to answer questions and that kind of drove me too. Knowing the answers felt good, and the professors starting counting on me and stuff and I didn't want to let that go...I didn't want to give that up. (Trevor, 19, African American Male)

Week after End of Semester. Q. Now that the semester is over, looking back, what do you think was most significant in getting you the final grade results that you got?

A. ...The first two papers I handed in were late and I got Ds, and two other assignments I did, I was told to redo them. It really shook me because I thought I was ready. Like we talked about back in September, that was the first time I can remember having any kind of doubts about school ....I don't know why I didn't take it more serious, I guess I just thought I would continue to do good, or maybe I just didn't think...I found high school kind a easy, but looking back, I think that was because my mom was always on top of me. She'd always be asking, did I do my homework, getting me up in the morning, and all of that...I guess I had a false sense of security, like it was all good before, why should that change. (Manuel, 19, Hispanic Male)

Early diligence was a common characteristic of the successful students, and proved crucial because it not only set the trend for how the rest of the semester would turn out, but these early experiences often impacted directly on the student's eventual academic self-esteem, as well as the degree of effort extended.

Patricia's (successful student) and Jasmine's (unsuccessful student) mid-semester reflections on how they then viewed themselves as college students illustrates the potential impact of early performance on academic self esteem well:

Week Seven $Q$. Given that the semester is about half over, I'd like to ask you how you currently view yourself as a college student?

A. It's funny that you ask that now because up until like a week ago or something I still didn't really look at myself as a college student. In a weird way I still felt like I was in high school. But after I got my mid-terms back I feel like I do belong here...I could see the pay-off between how much I studied at the beginning and all the work I did, and getting good grades. It's like now I feel like I really can do it, like I belong...now it's like I can actually think about my major (student was undecided about her major at this point) because it's a real thing. I will graduate, and not take seven years like a lot of people. (Patricia, 18, Italian American Female)

Week Seven Q. Given that the semester is about half over, I'd like to ask you how you currently view yourself as a college student?

A. To be honest I'm getting worried for the first time. I've never gotten grades like this and if I'm honest with myself I got to question my ability. I mean one bad grade here or there is not that big a deal, but I'm struggling. If I don't pick it up soon I might fail some of these courses. That would be so embarrassing... This is not how I pictured college to be... I think I can do it, but it's not like a sure thing like I used to think about it. (Jasmine, 18, White Female) 
In essence, the relatively early portion of the students' academic experiences had disproportionately powerful impacts on the students' academic self-esteems and often engendered significant optimism or pessimism for how the entire semester would then unfold. The perception of these early experiences often resulted in self-fulfilling prophecies that either encouraged or discouraged students from putting forth the necessary focus and effort to succeed.

When asked, $6 / 8$ of the successful students reported that their academic confidence had risen after the first month, while only $1 / 7$ of the unsuccessful students reported such an increase. Furthermore, during mid-semester interviews virtually all of the successful students (7/8) expressed feeling energized or motivated by their early successes. Conversely, 5/7 of the unsuccessful students reported feelings of discouragement and/or hopelessness, at least in part due to poor early performance.

\section{Discussion}

Though the specific findings presented here are unique to the study participants, several of the overall themes are reflected somewhat in the research literature.

\subsection{Active Help Seeking}

The academic efficacy of active help seeking tendencies, specifically among statistically "at-risk" students has been documented in several works, particularly from the burgeoning field of academic resilience (Morales \& Trotman, 2011; Morales, 2008) as well as in traditional works on student transitioning and involvement (Astin, 1984; Terenzini, 1994). Furthermore, a critical element of help seeking is the establishment of valuable relationships between students and faculty/administrators who can be of help. There is a good deal of literature concerning the mentoring of college students that speaks to the value, importance, and nature of this phenomenon (Morales, 2010; Sanchez, Reyes \& Singh, 2006; Stanton-Salazar \& Spina, 2003; Zalaquett \& Lopez, 2006). Finally, from a psychological perspective, the students' willingness and ability to reach out for help closely reflects Rotter's (1966) seminal work on internal locus of control. These students believed that taking action would benefit them (reflective of an internal locus of control), and therefore continually possessed the inclination to reach out. Specifically, this refers to the students' belief in their own abilities to influence their immediate environment, and thus achieve their goals. This presence of an internal locus of control has consistently been cited as a crucial ingredient of success among at-risk college students (Borman \& Overman, 2004; Demos, 1989).

\subsection{Managing Free Time and the Dangers of Underestimating Academic Rigor}

While the value and importance of effective time management have received a good amount of attention in the higher education research literature (Vandermeer, Jansen, \& Torenbeek, 2004), Goleman's (1995) groundbreaking work on emotional intelligence closely reflects how the students in the study effectively managed both themselves and their time. Goleman believes that people with high emotional intelligence manage both their time and emotions well, and thus are able to delay gratification in order to achieve a stated goal. Particular to college students, Goleman's work closely resembles that of Wolters (1998) who emphasizes the value and importance of self-regulation and motivation, as well as that of Nota, Soressi \& Zimmerman (2004) who identified self and time regulation as crucial to academic success.

A specific approach to effectively managing time for the students in this study was their tendency to create structure for themselves (e.g. going to the library on a regular basis, beginning assignments early, etc.). This tendency (or lack thereof) was often based on the student's ability (or inability) to estimate academic rigor realistically. Vandermeer, Jansen, and Torenbeek (2004) found that students who accurately predicted the difficulty of college level work were more likely to succeed, and Wyatt, Saunders, and Zelmer (2005) found that faculty felt that college students consistently underestimated the amount of effort that would be necessary in order for the students to do well in college classes. However, as Meyer, Spencer, and French (2009) point out, research on college students' perceptions of academic rigor is rare, thus making connections between perceptions, effort, and outcome difficult to achieve.

\section{3 "Early Diligence" -The Crucial Nature of the First Two Weeks}

While there is little research focusing explicitly on the academic importance of the very first weeks of students' college careers, in a more general sense, the disproportionate influence of the students' early academic feedback is highly reflective of both Rotter's (1966) previously mentioned notion of locus of control, as well as Bandura's (1997) widely cited work on self-efficacy. Early success strengthened the students' internal loci of control and resulted in a stronger sense of self-efficacy. Additionally, Hu and Kuh (2002) identified intrinsic goal motivation as a key for college student success, while self-efficacy was determined to be essential by Dennis et. al., (2008). Furthermore, Bandura posits that self-competence is promoted through mastery of experience (in this case, the students' early college challenges) and that individuals will put forth more effort when they have experienced prior success. As explored earlier, this can manifest 
either positively or negatively; while early success engenders feelings of confidence and ultimately more effort, early failure can lead to despair, insecurity, and less effort.

\section{Practical Implications}

The most rewarding aspect of conducting research focused on how students manage academic challenges is applying what has been learned to assist others. Even if only relatively modest changes are made and relatively few students helped, it is valuable work. Furthermore, while this is a qualitative study, thus making extrapolation of findings limited, there are specific interventions that appear to make sense based on these outcomes.

\subsection{Active Help Seeking}

Overall, the need to both maximize resources available to college students, and just as importantly to instill in students the desire and ability to actively seek out help, have been reinforced by the findings here. The latter challenge is particularly difficult to achieve. While many students in this study continued to seek out help because they were both cognizant and appreciative of positive results, other remained somewhat isolated, despite feeling badly about their lack of progress.

What educators can do is continue to actively reach out to students offering assistance, and to do so in deliberate ways. This may mean requiring more contact, especially early contact, with academic advisors or other college personnel. Additionally, given what the students in the study had to say about not feeling comfortable with some of their assigned advisors, increased training and professional development for those charged with guiding students should be facilitated. Specifically, an emphasis on forming strong relationships with students early in their academic careers should be encouraged. Once the students in this study felt comfortable going to advisors, they tended to seek out assistance both more quickly and frequently.

A way of more actively encouraging such valuable relationships would involve providing structured mentoring programs for freshmen students, particularly those who are first generation.

Whether the mentors would be upperclassmen, faculty, or administrators, the freshmen could benefit by having knowledgeable human resources whom they could turn to in times of confusion.

Finally, an overriding focus for quality guidance and advisement should be on instilling in students the habit of actively seeking assistance when facing challenges. As with most habits, early positive experiences should result in increases in the desired behavior.

\subsection{Managing Free Time}

The promotion of effective time management skills among students has long been a goal for college educators. Workshops, guidebooks, planners, and calendars focused on teaching time management are prevalent on most college campuses. However, despite these initiatives and resources, the challenge remains.

For the successful students in this study, self-imposed structure was a key. These students created their own time configurations and benefitted greatly. In order to help other students do this, colleges should work to create as much structure as reasonably possible for their new students. How this can be done depends greatly on the specifics of student and institution, but possible ideas include mandatory study hours, more frequent and smaller/incremental initial classroom assignments (as opposed to long term projects), expanded library hours, and increased daytime classes. Furthermore, time management workshops can focus more intensely on the value and importance of learning how to self-impose ample amounts of structure.

\subsection{The Dangers of Underestimating Academic Rigor}

It is difficult to overstate the potential damage of underestimating what it will take to succeed in college. As the results of this study indicate, there is a healthy sense of anxiety that new college students should have about the degree of rigor they will have to face. Students must get the message that just because something worked in high school does not mean that it will necessarily work in college. And while many of the successful students in this study seemed to have this healthy degree of concern upon beginning their higher education careers, colleges can and should help impart this valuable message. Here it may be especially important for faculty teaching predominantly freshmen to make this point explicitly at the beginning of the semester. Having professors do this in their courses may help create the sense of urgency needed to drive the message home. Faculty can also make certain to talk in detail about how the expectations and requirements for their classes may differ from what students may have been used to in high school. By clearly and plainly emphasizing these distinctions, the important difference between high school and college may become clear to students. 


\section{4 "Early Diligence" -The Crucial Nature of the First Two Weeks}

What became clear based on the data here was that the first two weeks of the semester had a disproportionate influence on these students' perceptions of themselves as college students, as well as their ultimate academic outcomes. In general, colleges should take steps to emphasize the critical nature of this time period to the entire academic community. This is an area where college faculty and academic administrators can make structural changes that can improve students' chances of success. When possible, the initial course assignments should include a good deal of academic scaffolding and support so that chances of early success are increased. Additionally, students should be provided with detailed formative feedback on these assignments so that they know both where they stand, and what, specifically, they will need to do in order to be successful. If students can have positive early experiences, and preferably see the payoff of their efforts, academic self-esteem can be enhanced and eventual success encouraged.

\section{Implications for Future Research}

While there has been a good deal of research done on college student performance, persistence, and experiences, the complexity of the phenomena, as well as changes in student demographics, culture and background, make continued focus necessary. Particular to the present study, there are three major implications evident.

First, as with all qualitative studies, the findings here are primarily reflective of only the fifteen students included in the sample. As a consequence, the findings can and should be tested through quantitative studies with larger sample sizes. Through such studies the particular natures of the help seeking tendencies of new students can be further elucidated, as could student responses to unexpected amounts of free and unstructured time. Specific work focused on the possible correlation between degree of students' academic confidence and ultimate success could also be determined. Similarly, in-depth studies of how academic performance during the first two weeks of a semester may impact ultimate achievement levels could prove highly valuable and relevant to the structuring and content of freshman college courses.

Second, the approach of looking at both successful and unsuccessful students and comparing and contrasting their experiences is ripe for further study. A dual and simultaneous look at what works and what does not work can help inform best practices when designing programs to help students succeed. Such studies can create models of both what to do and what not to do in specific situations and contexts.

Finally, the process of "real time" longitudinal research that captures what students are currently experiencing and allows them to reflect at the end of an academic episode, can be exceptionally valuable. This research approach allows for findings that more closely reflect real life experience. Additionally, the process of this type of research allows the researcher to provide a temporal analysis of the students' experiences, thus allowing for the possibility that at various moments different resources may be more efficacious than others. Again, the approach can be useful because it both reflects and respects the complexity of experience.

\section{References}

American Federation of Teachers: Campus Clips (2011). First year students ambitious, optimistic and overwhelmed. AFT On Campus, (30)5, 2.

Astin, A. W. (1984). Student involvement: A developmental theory for higher education. Journal of College Student Personnel, 25, 297-308.

Astin, A. W. (1993). What matters in college? Four critical years revisited. San Francisco: Jossey-Bass.

Attinasi, L. (1989). Getting in: Mexican Americans' perceptions of university attendance and the implications for freshman year persistence. Journal of Higher Education, 60(3), 247-277.

Bai, H. \& pan, W. (2009). A multilevel approach to assessing the interaction effects on college student retention. Journal of College Student Retention, 11(2), 287-301.

Bandura, A. (1997). Self-efficacy: The exercise of control. New York: Freeman.

Bogdan, R. \& Biklen, S. (1982). Qualitative research for education: An introduction to theory and methods. Boston: Allyn and Bacon.

Borman, G. \& Overman, L. (2004). Academic resilience in mathematics among poor and minority students. Elementary School Journal, 104(3), 177-197.

Clark, M. (2005). Negotiating the freshman year: Challenges and strategies among first-year college students. Journal of College Student Development, 46(3), 296-317. 
Clark, M. \& Cundiff, N. (2011). Assessing the effectiveness of a college freshman seminar using propensity score adjustments. Research in Higher Education, 52(6), 616-639.

Creswell, J.W. (2005). Educational research. Upper Saddle River, NJ: Pearson.

Demos, E.V. (1989). Resiliency in infancy. In T. Dugan \& R. Coles (Eds.), The child in our times: Studies in the development of resiliency (pp. 3-22). New York: Brunner- Mazel.

Dennis, J., Calvillo, E. \& Gonzalez, A. (2008) The role of psychosocial variables in understanding the achievement and retention of transfer students at an ethnically diverse urban university. Journal of College Student Development, 49 (6) 535- 550 .

Gardner, S. \& Karri, H. (2011). Those invisible barriers are real: The progression of first generation students through doctoral education. Equity \& Excellence in Education, 44(1), 77-92.

Geertz, C. (1973). Thick description: Toward an interpretive theory of culture. In C. Geertz (Ed.), The interpretation of cultures (p. 3-30). New York: Basic Books.

Ely, M. (1991). Doing qualitative research: Circles within circles. New York: The Falmer Press.

Gardner, D. (2007). Confronting the achievement gap. Phi Delta Kappan, (88)7, 542-546.

Goleman, D. (1995). Emotional intelligence. New York: Bantam Books.

Hu, S. \& Kuh, G. (2002). Being disengaged in educationally purposeful activities: the Influences of student and institutional characteristics. Research in Higher Education, 43 (5) 555-575.

Hudson, W., Henderson, D., \& Henderson, J. (2002). The retention of entering freshmen enrolled at Florida A\&M University's School of General Studies during the fall semesters 1997- 2001. Education, 1, 2011-212.

Horwedel, D. (2008). Putting first-generation students first, Diverse Issues in Higher Education, 25(5), 10-12.

Jacobs, J. \& Archie, T. (2008) Investigating sense of community in first-year college students. Journal of Experiential Education, 30(3) 282-285.

Kirk, J. \& Miller, M. (1986). Reliability and validity in qualitative research. Beverly Hills, CA: Sage.

Lang, M. (1986). Black student retention at predominantly black institutions: Problems issues alternatives. Western Journal of Black Studies, 10(2), 48-54.

Lang, M. (1992). Barriers to Blacks' educational achievement in higher education: a statistical and conceptual review. Journal of Black Studies, 22, 510-522.

Meyer, M. Spencer, M. \& French, N. (2009). The identity of a college student: Perceptions of college academics and rigor among first-year college students. College Student Journal, 43(4), 1070-1079.

Morales, E.E. (2008). The resilient mind: The Psychology of academic resilience. The Educational Forum (KDP), 72(2), 152-167.

Morales, E.E. (2010). Legitimizing hope: An exploration of mentoring for Dominican American male college students. Journal of College Student Retention: Research, Theory, \& Practice, 11(3), 385-406.

Morales, E.E. \& Trotman, F.K. (2011). A focus on hope: 50 resilient students speak. Rowman Littlefield/University Press of America Press. Lanham, MD.

McCracken, G. 1988. The long interview. Newbury Park, CA: Sage.

Nota, L., Soressi, S. \& Zimmerman, B. (2004). Self-regulation and academic achievement and resilience: A Longitudinal study, International Journal of Educational Research, 41(3), 198-215.

Pascarella, E. T., and P. T. Terenzini. (1991). How college affects students: Findings and insights from twenty years research. San Francisco: Jossey-Bass.

Perna, L.W. (2005). The Benefits of higher education: Sex, racial/ethnic, and socioeconomic. Review of Higher Education, 29(1), 23-52.

Phinney, J. S., \& Haas, K. (2003). The process of coping among ethnic minority first-generation college freshmen: A narrative approach. Journal of Social Psychology, 143, 707-726.

Princeton Review's Complete book of colleges (2010) Princeton Review, Framingham MA. 
Ridgell, S. \& Lounsbury, J. W. (2004), Predicting collegiate academic success: General intelligence, personality traits, and work drive. College Student Journal, 38, 607-618.

Rotter, J. (1966). Generalized experiences for internal versus external control of reinforcement. Psychological Monograph, 80(1), 609- 621.

Rubin, H. \& Rubin, I. (1995). Qualitative interviewing: The art of hearing data. Thousand Oakes, CA: Sage Publications.

Sanchez, B., Reyes, O., \& Singh, J. (2006). Makin' it to college: The value of significant individuals in the lives of Mexican American Adolescents. Journal of Hispanic Higher Education, 5(1), 48-67.

Sedlacek, W. E. (1996). Employing noncognitive variables in admitting students of color. In H. Johnson, \& A. J. Ottens (Eds.), Leveling the playing field: Promoting academic success for students of color. Thousand Oakes, CA: Sage Publications.

Seidman, A. (2007). (Ed). Minority student retention: The best of the Journal of College Student Retention. Amityville, NY: Baywood.

Spradley, J. (1979). The ethnographic interview. New York: Holt, Reinhardt \& Winston.

Stanton-Salazar, R., \& Spina, S. U. (2003). Informal mentors and role models in the lives of urban Mexican-origin adolescents. Anthropology \& Education Quarterly, 34(3), 231-254.

Terenzini, P., Springer, L., Yaeger, P.M., Pascarella, E.T., \& Nora, A. (1994). The transition to college: Diverse students, diverse stories. Research in Higher Education, 35(1), 57-73.

Tinto, V. (1993). Leaving college: Rethinking the causes and cures of student attrition (2nd ed.). Chicago: University of Chicago Press.

U.S. Department of Education. (2009). Institute of education sciences. [Online] Available: http://nces.ed.gov/programs/digest/d09/tables/dt09_331.asp

Vandermeer, J. Jansen, E. \& Torenbeek, M. (2004). It's almost a mindset that teachers need to change: First-year students need to be inducted into time management. Studies in Higher Education, 35(7), 777-791.

Watson, L. \& Watson-Frank, M. (1985). Interpreting life histories: An Anthropological inquiry. New Brunswick, NJ: Rutgers University Press.

Wolters, C. A. (1998). Self-regulated learning and college students' regulation of motivation. Journal of Educational Psychology, 90, 224-235.

Wyatt, G. Saunders, D. and Zelmer, D. (2005). Academic preparation, effort and success: A comparison of students and faculty perceptions. Educational Research Quarterly, 29(2), 29-36.

Zalaquett, C. P., \& Lopez, A. D. (2006). Learning from the stories of successful undergraduate Latina/Latino students: the importance of mentoring. Mentoring \& Tutoring: Partnerships in Learning, 14(3), 337-353. 